\title{
LAS ANTENAS DE TELEFONÍA MÓVIL
}

\section{MOBILE ANTENNAS}

Juan Carlos Martínez: Universidad de Alcalá de Henares (Madrid-España). jc.martinez@aol.com

\section{CURRÍCULUM VITAE}

Licenciado en Medicina, pertenece al Staff de la Universidad de Alcalá de Henares donde es profesor en Ciencias de la Salud. Las materias que imparte son Patología General, Patología Médica y Clínica Médica.

\section{RESUMEN}

La telefonía móvil ha ocupado, en los últimos años, un lugar indispensable en nuestras vidas. Nos acompaña allí donde vamos, ofreciéndonos una comunicación constante. Con su desarrollo también han aparecido las grandes antenas repetidoras. El problema es que desde las instituciones y organismos públicos se ha generado un globo sonda que no termina de aclarar si estos dispositivos pueden resultar perjudiciales para la salud.

\section{PALABRAS CLAVE}

Teléfono móvil - Antena - Salud 


\section{ABSTRACT}

Mobile telephony has taken in recent years, an indispensable place in our lives. Accompanies us wherever we go, offering constant communication. With their development have also appeared large masts. The problem is that from the institutions and government agencies has led to a balloon that fails to clarify whether these devices can be harmful to health.

\section{KEY WORDS}

Mobile Phone - Antenna - Health

\section{ÍNDICE}

1. Introducción

2. Características de las telecomunicaciones

TEXTO:

\section{Introducción}

La telefonía móvil ha ocupado, en los últimos años, un lugar indispensable en nuestras vidas. Nos acompaña allí donde vamos, ofreciéndonos una comunicación constante. A la vez que estos aparatitos, han aparecido, en muchas azoteas de nuestras viviendas, unas grandes antenas repetidoras. 
Hace poco los medios de comunicación y algunos Ayuntamientos nos han hecho dudar de si estos útiles dispositivos pueden resultar perjudiciales para la salud. Incluso se ha asegurado que los casos de Leucemia (Cáncer) aparecidos en una localidad de Valladolid y Zaragoza se deben a la telefonía móvil, sobre todo a sus repetidores.

¿Cuánto de esto es verdad? Las autoridades sanitarias aseguran que no hay peligro, pero mucha gente desconfía de dicha afirmación sabiendo la gran cantidad de dinero que mueve la telefonía móvil. Esta breve nota intenta responder, en parte, a esta pregunta.

\section{Características de las telecomunicaciones}

Hoy día la banda de radiofrecuencia está prácticamente utilizada por completo. Desde la radio hasta el radar, pasando por las televisiones públicas y privadas, la telefonía móvil y las emisoras de urgencias, policiales y de radioaficionado. A continuación muestro una tabla genérica de las frecuencias utilizadas:

\begin{tabular}{|c|c|c|c|}
\hline Banda & Abreviatura & Frecuencia & Servicios típicos \\
\hline 4 & VLF & 3 a $30 \mathrm{kHz}$ & Navegación, Sonar \\
\hline 5 & LF & 30 a $300 \mathrm{kHz}$ & Radioayudas, Radionavegación \\
\hline 6 & MF & 300 a $3000 \mathrm{kHz}$ & $\begin{array}{c}\text { Emisoras AM, Radio Marítima, } \\
\text { Radiobalizas }\end{array}$ \\
\hline 7 & HF & 3 a $30 \mathrm{MHz}$ & $\begin{array}{c}\text { Telefonía, Telégrafo, Facsímil, } \\
\text { Emisoras de onda corta, } \\
\text { Radioaficionados, Banda } \\
\text { Ciudadana }\end{array}$ \\
\hline 8 & VHF & 30 a $300 \mathrm{MHz}$ & $\begin{array}{c}\text { TV, Emisoras FM, Control de } \\
\text { Tráfico Aéreo, Policía, } \\
\text { Radionavegación }\end{array}$ \\
\hline 9 & UHF & 300 a $3000 \mathrm{MHz}$ & $\begin{array}{c}\text { TV, Comunicaciones por Satélite, } \\
\text { Radiosondas, Radar de }\end{array}$ \\
\hline
\end{tabular}




\begin{tabular}{|c|c|c|c|}
\hline & SHF & 3 a $30 \mathrm{GHz}$ & $\begin{array}{c}\text { Emergencia, Radionavegación, } \\
\text { Comunicaciones Móviles }\end{array}$ \\
\hline 10 & $\begin{array}{c}\text { Radar Aerotransportado, } \\
\text { Radioenlaces, Comunicaciones } \\
\text { móviles, Comunicaciones por } \\
\text { Satélite }\end{array}$ \\
\hline 11 & EHF & $30 \mathrm{a} 300 \mathrm{GHz}$ & Radar \\
\hline
\end{tabular}

\section{La telefonía GSM se encuentra en la banda de 900 kHz a 1 GHz.}

Nos podríamos plantear una pregunta: al colocar una torre repetidora en una azotea, ¿en qué dirección y sentido se emite la onda? La respuesta es a los edificios de alrededor, poniéndose de manifiesto un fenómeno conocido como "efecto paraguas". Basta colocar una tela metálica especial, que no deja pasar la señal, muy barata, y el edificio donde se instaló la torre estará fuera del alcance de la señal emitida. Esto se ve mejor de forma gráfica:

Otro factor importante en la emisión de señales e incidencia de las mismas es el coeficiente de absorción. Este coeficiente nos dice qué cantidad de energía de una 
señal emitida es absorbida por nuestro cuerpo, es decir, en qué medida puede afectar a la salud. Toda señal se puede descomponer en varias partes, en este caso vamos a descomponer la señal en tres partes: la parte incidente (A), la parte reflejada (B), y la parte que atraviesa el material (C). De esto sale una ecuación cuya resultante es la cantidad de señal absorbida por el cuerpo, para verlo mejor observe el siguiente gráfico:

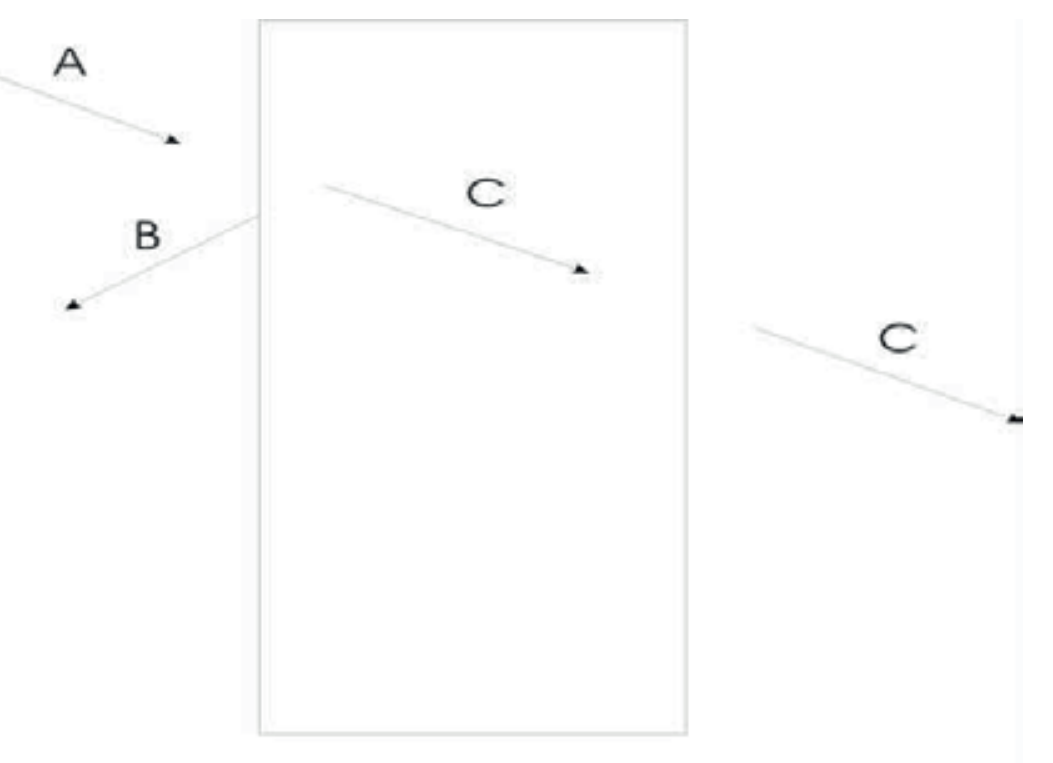

Absorción $=A-(B+C)$

Cualquier estudio serio sobre este tema, deberá ir acompañado del análisis de las características anteriores, para poder informar a la opinión pública verazmente. Desde estas páginas hacemos un reto a nuestros lectores, para que nos envíen las contribuciones al respecto, que serán publicadas en la nueva sección de Vivat Academia, titulada "Ambiente y Salud" (me comprometo a ser uno de los colaboradores). 
He de agradecer al Doctor José Luis Bardasano Rubio, Director del Departamento de Especialidades médicas de la U.A.H., y al Doctor Sebastián Sánchez Prieto, profesor de esta misma universidad, su ayuda en la redacción de esta nota. 